\title{
Cidade, Memórias e Sensibilidades
}

\section{City, Memories and Sensibilities}

\author{
Maria Silvia Duarte Hadler
}

msilviadh@uol.com.br

Resumo

$\mathrm{Na}$ abordagem das complexas relações entre cidade, modernidade, memória e sensibilidades, este artigo procura compreender articulações entre traços culturais da contemporaneidade e as singularidades da dinâmica sociocultural de uma determinada localidade, no caso a cidade de Campinas (SP). Pretende, portanto, trazer momentos significativos para a constituição de processos socioculturais favorecedores do fortalecimento de formas de sociabilidade calcadas no individualismo urbano, propiciadoras da fragilização de vínculos com os diferentes lugares da cidade. Assim, os anos finais de 1950 e os de 1960 são o momento e o cenário de constituição de formas de educação urbana das sensibilidades que apontariam para aqueles processos socioculturais período em que a paisagem urbana sofre sucessivas modificações e passa a ser mais intensamente marcada pelos ritmos mais acelerados dos automóveis.

Palavras-chave: Cidade; Sensibilidades; Modernidade.

\begin{abstract}
In addressing the complex relationships between city, modernity, memory and sensibilities, this article seeks to understand linkages between cultural features of the contemporary and the singularities of the sociocultural dynamics of a particular locality, in case the city of Campinas (SP). Therefore aims to bring significant moments for the constitution of sociocultural processes favoring the strengthening of forms of sociability based on urban individualism, which encourage the weakening of ties to different places of the city. Thus, the final years 1950 and 1960 are the time and the scene of creation of forms of urban education of sensibilities that would point to those sociocultural processes - period when the urban landscape undergoes successive changes and becomes more strongly marked by faster pace of the car.
\end{abstract}

Keywords: City; Sensibilities; Modernity.

1 Pesquisadora do Centro de Memória - Unicamp (CMU). Doutora em Educação na área de Educação, Conhecimento, Linguagem e Arte, pela Faculdade de Educação da Unicamp (FE/Unicamp). Pós-doutorado realizado sob supervisão da Profa. Dra. Maria Carolina Bovério Galzerani (1947-2015). 
Artigos

Ao pesquisar vídeos informais sobre a cidade de Campinas (SP) no Youtube, nos deparamos com três, de diferentes autores, que chamam a atenção pela maneira como abordam a cidade. ${ }^{2}$

Com um clique do mouse, o vídeo de três minutos, enviado em 16/02/2010, se inicia. O título já designa a temática: "Um passeio noturno por algumas avenidas de Campinas, São Paulo". O passeio se inicia: as imagens são produzidas do interior de um automóvel que não vemos e apenas o som do motor deste automóvel nos faz companhia por esse passeio noturno. Enquanto espectadores, somos levados a percorrer um itinerário de avenidas que se sucedem e se interligam, cortando áreas centrais da cidade e bairros próximos ${ }^{3}$. Não há movimento de pedestres nas ruas, nem há trânsito neste momento da noite - é possível que seja de madrugada. Há apenas o automóvel e as avenidas, os personagens principais. Este automóvel que não se deixa ver no vídeo, mas que é o condutor da construção da sequência de imagens, não seria emblemático da vida moderna em nossas cidades? Um personagem onipresente a comandar os ritmos da vida urbana, mesmo que não esteja fisicamente presente em diversas situações desta vida urbana; simboliza, talvez, um dos traços essenciais da modernidade - a velocidade e o estar em trânsito, de passagem - as pessoas não estão presentes, parecem não ter importância. Em foco, as avenidas, luzes noturnas, espaços vazios, não-lugares.

Outro vídeo, enviado em 02/02/2012, vem acompanhado do recado de seu autor a possíveis espectadores: "vídeo que eu gravei aqui em Campinas ao passear pelos bairros perto do centro, gosto muito daqui, pra mim é um ótimo lugar para morar, adoro esta cidade maravilhosa". E quais são as imagens oferecidas sobre esta "cidade maravilhosa", "ótimo lugar para morar"? Surpreendentemente, o recorte da cidade que nos é oferecido em dois minutos mostra o trânsito pesado e agitado da Rodovia D.Pedro cortando bairros mais populares e áreas de comércio atacadista como o Makro. É através do gradil verde de uma passarela de pedestres que temos acesso às imagens movimentadas.

Em outro pequeno vídeo de menos de dois minutos, postado em 12/01/2012, entramos em contato com imagens semelhantes - é realizada a filmagem em uma das alças do Viaduto Miguel Vicente Cury, em sua parte mais alta, em direção ao centro da cidade: trânsito carregado, muitos automóveis e ônibus passando, entrevendo-se ruas do entorno também muito movimentadas, com o horizonte demarcado por inúmeros edifícios altos.

Um personagem comum aos três vídeos é o movimento. A cidade retratada é a que pulsa sob os ritmos agitados e velozes de veículos motorizados. Eles dominam a cena. As pessoas, em suas andanças por estes trajetos, não são focalizadas, apenas os sinais indicadores da existência humana são privilegiados - construções e veículos.

Estes vídeos encontrados, não por coincidência, parecem nos mostrar sinais de uma determinada sensibilidade urbana. Uma determinada forma de percepção da cidade solidária da movimentação incessante. Poderíamos, talvez, ler estes vídeos como uma forma de elogio à velocidade e às grandes avenidas que oferecem suporte material à concretização da velocidade. Poderíamos lê-los, também, como indicadores do individualismo urbano: não são focalizados lugares de encontro, de convivência, mas, sim, de passagem, de trânsito rápido.

Uma questão se coloca à nossa reflexão: quais as condições históricas de constituição destas formas de sensibilidade? Em que momentos da modernidade estas formas de percepção da vida urbana tiveram mais possibilidades de se desenvolver?

A modernidade se instala na história sob o signo do movimento e da aceleração dos ritmos sociais. Impactos culturais significativos trazidos pelo tempo da modernidade capitalista engendraram novas percepções sobre relações entre tempos, ritmos e espaços. Os espaços urbanos e, em especial, as grandes cidades, colocam-se como as instâncias materiais de concretização destes processos. Sensibilidades modernas vão sendo conformadas nestes espaços marcados por modificações constantes e rápidas ${ }^{4}$.

O sujeito moderno urbano tem sua sensibilidade formada sob o impacto da fragmentação, do efême-

2 Disponível em: < http://www.apenaspensando.com.br>. Acesso em: 20 jul. 2013.

3 O trajeto percorrido parte da Av. Abolição, chega à Morais Sales, mais ao centro, acessa a Av. Anchieta, passando em frente ao prédio da Prefeitura Municipal, atinge a Av. Orosimbo Maia, a Av. Norte-Sul, chegando à Princesa D’Oeste, depois à Comendador Enzo Ferrari, chegando finalmente à Av.'Tibiriçá.

4 Discussões acerca de relações entre modernidade, memória e cultura urbana foram desenvolvidas ao longo de minha pesquisa de tese de doutorado "Trilhos de modernidade: memórias e educação urbana dos sentidos", sob a orientação da profa. Dra. Maria Carolina Bovério Galzerani, defendida em fevereiro de 2007 na FE/Unicamp. Essas discussões foram desenvolvidas através da presença e circulação dos bondes no espaço urbano, os quais, considerados símbolos de progresso no início do século XX e de atraso e obsolescência nos anos 60, desempenharam um papel significativo nestes processos de constituição de sensibilidades modernas. 
ro, do transitório, da fluidez que permeiam sua experiência de tempo e espaço (BRESCIANI, 1997). A questão da constituição da experiência do sujeito na cidade moderna se apresenta, portanto, como uma temática fundamental, sobre a qual diversos autores têm largamente se debruçado ${ }^{5}$.

Pela mediação de meios de transporte e de tecnologias da comunicação e da informação, os espaços urbanos têm sofrido a tendência de se tornarem espaços praticamente ilimitados, por um lado e, por outro, de se tornarem espaços que favorecem práticas socioculturais limitadas, segmentadas (MONGIN, 2009). Relações sociais permeadas por diversas formas de individualismo urbano se aliam às tendências crescentes de fragilização dos vínculos que se mantêm com os diversos lugares das cidades (SENNETT, 1997; 1998). Os ritmos intensos e velozes que impulsionam a vida cotidiana nos impelem a circular, a estar constantemente de passagem pelos diversos espaços e lugares da cidade, promovendo uma diluição de possíveis vínculos com estes diversos lugares.

Nos últimos anos, a mobilidade urbana tem se tornado uma questão urgente nas grandes cidades em geral e, em especial, nas grandes cidades brasileiras também. Seus habitantes vivem às voltas com constantes congestionamentos, deficiências do transporte público, automóveis em excesso, situação favorecida por políticas de estímulo ao consumo. Relações virtuais vêm mediando, cada vez mais, o contato entre as pessoas. Superficialidade nas relações interpessoais e uma boa dose de imediatismo acompanham a valorização da rapidez nas ações e resoluções. As tendências observadas de constituir moradia em condomínios residenciais fechados aprofundam processos de segregação do espaço urbano.

A aceleração do tempo urbano tem propiciado, em diversos momentos da modernidade, descaracterizações de espaços urbanos, dificultando possibilidades de memórias e de experiências mais significativas. Referenciais de identificação e de localização do indivíduo no espaço da cidade e no conjunto das relações sociais tendem a passar por processos de apagamento.

Como pensar, então, a questão da experiência na cidade contemporânea? Como pensar formas de sociabilidades e de sensibilidades que estariam, então, se constituindo neste cenário urbano?

O sociólogo Georg Simmel (1976), nos anos iniciais do século XX, também se preocupou em entender melhor as condições de existência do indivíduo urbano moderno: o sujeito metropolitano, vivenciando uma mercantilização maior das relações sociais, procuraria preservar sua subjetividade contra o "poder avassalador" da vida da grande cidade, desenvolvendo uma postura de autopreservação, de maior racionalidade, expressa num comportamento mais reservado, dotado de maior indiferença.

Walter Benjamin, em diálogo com as reflexões de Simmel e também de Freud, ressalta que a ameaça de energias externas ao indivíduo se faria sentir através de choques, que seriam atenuados, amortecidos por mecanismos de controle dos estímulos externos, desenvolvidos pelo consciente. A vivência nas grandes cidades aproximaria ou imergiria seus habitantes na experiência do choque da modernidade. A constância da ocorrência destes choques nas sensibilidades, desenvolvendo mais a capacidade de racionalização, faria com que a vida numa grande cidade levasse seus habitantes a deixarem de viver experiências mais compartilhadas, de contato mais direto entre as pessoas, para terem vivências, noção que apontaria para situações de isolamento, não partilha, menor aproximação, distanciamento de relações mais próximas e emocionais.

A velocidade e a intensidade do avanço da modernidade em dimensões cada vez mais amplas da vida social teriam produzido alterações nas formas de comunicação entre as pessoas. O tempo que permitiria formas de intercâmbio, de compartilhamento de experiências, o tempo da narrativa, teria se tornado contraído ou até mesmo inexistente. Assim, de acordo com Benjamin, vivenciaríamos na sociedade contemporânea uma tendência de "atrofia crescente da experiência", atrofia esta que se torna mais visível no espaço das cidades modernas.

Richard Sennett (1997; 1998), preocupado com a conformação do individualismo urbano, também assinala a configuração de uma ética da indiferença e da passividade que impele o cidadão urbano moderno, cada vez mais, a se reduzir à figura do espectador, refugiando-se em seus espaços privados, diluindo o sentido do coletivo e do público.

5 Encontramos referenciais fundamentais de análise desta problemática na obra do filósofo alemão Walter Benjamin, como também na do sociólogo G.Simmel. Autores mais recentes, com diferentes abordagens, também têm trazido a problemática da modernidade e da cidade em suas múltiplas dimensões socioculturais, como A.Giddens, R.Sennett, Peter Gay, Stuart Hall, Zigmunt Bauman, Gilles Lipovetsky. 
Artigos

No entanto, esta cidade moderna, em que pese a presença de todos esses traços culturais da modernidade, não se apresenta como um espaço unidimensional; ela se mostra polifônica, diversa, heterogênea, portadora de múltiplas histórias e memórias. A cidade também se apresenta como lugar das diferenças, da pluralidade de vozes, de gestos, corpos, olhares. Um espaço que abriga particularidades e singularidades, e que também é expressão de processos históricos culturais mais amplos.

A filósofa Anne Cauquelin, em seu belo trabalho Essai de philosophie urbaine (1982) nos remete às diversas camadas de memórias que recobrem o espaço urbano, memórias diversas que também são estruturadoras desse espaço, que conferem sentidos às relações sociais e políticas que configuram esse espaço urbano. Chama a atenção para um conjunto heterogêneo de memórias, memórias esquecidas ou rejeitadas, fragmentadas ou confusas que constituiriam um certo meio de que as cidades retirariam sua substância. A apreensão do espaço urbano passa por levar em conta as diversas temporalidades expressas por esse conjunto diversificado de memórias. Na linha de reflexão desenvolvida por Cauquelin, não se pode limitar a observação dos efeitos do tempo no espaço urbano às marcas visíveis nos edifícios, pois "nos traços materiais subsistem memórias gestuais, comportamentos diversos, com frequência devedores de estratos culturais sucessivos”(p.18).

Assim, este cenário nos estimula a perguntarmos como vivemos na cidade e como vivemos a cidade. Que vínculos que nós estabelecemos com a cidade que habitamos? E que cidade habitamos, dentre as várias cidades que são perceptíveis na própria cidade?

É preciso, portanto, atentar para as mediações significativas que permeiam a apreensão da cidade, de seus lugares, da dinâmica das relações sociais; compreender as formas de circulação pelo espaço urbano, e de vinculação com os diferentes lugares deste espaço. São aspectos que me parecem cruciais para uma abordagem das relações entre modernidade, cidade e sensibilidades, temas estes que se entrelaçam com as questões da memória e dos processos de constituição dos sujeitos.

No âmbito desta forma de abordagem, podemos nos propor a procurar compreender melhor como os traços gerais da moderna sociedade contemporânea se articulam com as singularidades da dinâmica sociocultural de uma determinada localidade - no caso, a cidade de Campinas (SP).

Os momentos em que o espaço urbano passa a ser mais intensamente percorrido pelos ritmos mais acelerados dos automóveis seriam cruciais para se compreender melhor alterações nas formas de percepção e de apreensão da cidade. Presentes no espaço urbano desde o início do século XX, ainda de forma discreta e tímida, estes meios de locomoção e de comunicação com o espaço urbano teriam no Brasil, na década de 1950, um momento fundamental de difusão e expansão. Sob a atmosfera do desenvolvimentismo da segunda metade da década, a indústria automobilística é incentivada, e o automóvel se torna um bem de consumo de maior alcance. Assim, localizo nos anos em torno das décadas de 1950 e 1960 a possibilidade dos processos socioculturais aludidos acima estarem se intensificando.

As rápidas modificações da paisagem urbana em Campinas, entre os anos finais da década de 1950 e os anos 1960, estariam configurando o cenário de constituição e aguçamento de formas de sensibilidade urbana, de percepção do mundo urbano como algo em processo de constante mutação. Assistimos, portanto, neste período, a uma aceleração dos ritmos urbanos, acompanhada de modificações e descaracterizações da paisagem urbana de então. A linguagem da verticalização já vinha dando sinais claros de que estava conquistando cada vez mais espaço em áreas mais centrais. O Plano de Melhoramentos Urbanos, idealizado na década de 1930, vinha, até então, sendo implementado lentamente. Definindo ruas a serem alargadas, áreas com construções a serem demolidas, apresentando propostas de reconfiguração da estrutura viária, com suas avenidas centrais e perimetrais, este Plano será concretizado de forma mais incisiva na segunda metade da década de 1950. Em especial, no período entre 1956 e 1962 ocorrerá uma intensificação do processo de demolições, construções e verticalização das áreas centrais. Constitui-se como o momento em que se desenrolará um processo mais radical de transformação da paisagem urbana. Uma nova estética urbana vai procurar se impor.

Inúmeras demolições se efetivam, acompanhadas de novas construções, em geral edifícios altos que encantavam o olhar dos admiradores da verticalização do centro. É o caso dos edifícios Anhumas (22 andares), Catedral (16 andares), José Kaufmann(12 andares), José Guernelli (20 andares). Segundo Carpintero,

Todas estas demolições no centro da cidade criaram uma sensação de destruição e ruptura, principalmente pela rapi- 
dez com que aconteceram. O Largo do Rosário no final do ano de 1956 tinha já sido entregue ao uso. Foram essas demolições que deram a imagem dos acontecimentos da época (CARPINTERO, 1996, p.70).

A verticalização no centro aponta, por um lado, para uma maior amplitude das atividades comerciais; diversas agências bancárias se fazem presentes. Por outro lado, aponta também para uma mudança relativa ao modo de morar: apartamentos residenciais passam a ser uma opção. Casas térreas e sobrados cedem espaço para apartamentos, enquanto as torres das igrejas, que antes se impunham na paisagem urbana, agora se encolhem, quase engolidas pelos edifícios.

A implementação do Plano de Melhoramentos Urbanos tem no automóvel um parceiro onipresente. As intervenções urbanísticas realizadas abriram espaço para uma melhor circulação de veículos, de pessoas e de mercadorias através das avenidas que se abriam. Essas intervenções foram solidárias de uma outra temporalidade urbana: prepararam melhor a cidade para a maior mobilidade e rapidez dos automóveis, para uma maior agilidade na condução dos negócios.

A reformulação do centro e de áreas próximas adentra os anos 60, acompanhada de novas demolições, incluindo a polêmica derrubada do Teatro Municipal em 1965. Uma outra temporalidade, e outros ritmos urbanos se fortalecem. Preparando-se a retirada definitiva dos bondes de circulação - o que se concretiza em 1968 -, ônibus, automóveis e seus padrões de mobilidade, velocidade, eficiência mostram-se mais condizentes com um perfil de urbanização que se encaminha no sentido de aprofundar segregações espaciais e desigualdades sociais.

Todo este processo de transformação da paisagem urbana teve um momento extremamente significativo na construção do Viaduto Miguel Vicente Cury - inaugurado em 27/01/1963 -, que pode ser tomado como emblemático da nova temporalidade urbana que está procurando se tornar hegemônica.

\section{A cidade do automóvel se impõe}

Este "majestoso viaduto, orgulho da engenharia municipal", substituía um antigo e modesto viaduto, uma passagem sobre os trilhos da Cia. Paulista de Estrada de Ferro, construído em 1928 e demolido em outubro de 1961. Estabelecia a ligação entre a entrada principal da cidade e avenidas internas que foram abertas, articulando-se com a estação ferroviária e possibilitando uma melhor distribuição do tráfego da área central. Considerado uma "exigência do progresso", pois "o tráfego no velho viaduto estava na iminência de colapso", o Viaduto Miguel Vicente Cury e avenidas próximas foram exaltados pela imprensa local como "um monumento marco para a eternidade", como "novas portas abertas ao progresso de Campinas", representando estas obras "o cartão de visitas" da cidade (CORREIO, 1963).

A ampliação do antigo viaduto já era sugerida pelo Plano de urbanismo de Prestes Maia nos anos 30, com a construção de uma nova pista que desse acesso às ruas estratégicas para a vazão do tráfego. Em 1948, o prefeito da época, Miguel Vicente Cury, na intenção de acelerar a execução do Plano, teria solicitado ao Departamento de Obras e Viação sua revisão. No entanto, as soluções propostas para o viaduto no plano revisto, aprovado em 1951, não foram realizadas devido às dificuldades de várias ordens, inclusive as relativas à necessidade de desapropriações. As próximas gestões municipais, instaladas em 1952 e $1956^{6}$, embora tivessem manifestado interesse na construção do novo viaduto, não levaram o plano adiante. Vai ser, portanto, na segunda gestão do prefeito Miguel Vicente Cury (1960-1963) que o novo viaduto, enfim, vai ser construído.

Feita uma seleção entre 33 anteprojetos apresentados, foi escolhido o que apresentava uma solução em rotatória, em formato elíptico, com a proposta de transformar numa espécie de parque ajardinado uma área de $20 \mathrm{mil} \mathrm{m}^{2}$ no interior dessa elipse. Em junho de 1960, então, a prefeitura constitui o que seria o órgão executor do projeto de construção ${ }^{7}$ - o Grupo Operação Viaduto (GOV) -, que deveria ser responsável, além da própria construção, por todas as questões relacionadas às desapropriações, desocupação e demolição dos imóveis existentes nas áreas necessárias à construção do novo Viaduto.

A contraposição do novo ao velho se fazia recorrente nas páginas dos jornais locais: "num esforço de memória, qualquer um poderá se recordar do velho viaduto da Paulista ... já obsoleto em face do progresso da Princesa do Oeste", e ainda,

6 Assumem a Prefeitura de Campinas, em 1952, Antonio Mendonça de Barros e, em 1956, Ruy Novaes.

7 O GOV foi criado em 30/06/1960 através do Decreto n 1.614, entrando imediatamente em atividade. O Dr.Carlos Grimaldi (secretário dos Negócios Internos e Jurídicos) e o Dr. Hélio Siqueira (subdiretor do Departamento Legal da Municipalidade) foram encarregados do aspecto legal das desapropriações. A direção da construção ficou sob a responsabilidade dos engenheiros Dr. Alberto Jordano Ribeiro (secretário de Obras e Serviços Públicos) e Dr. José Carlos Penteado de Freitas (diretor do Departamento de Obras e Viação). 
Artigos

[...] num exame retrospectivo poderá fixar em sua memória o velho casario que de sobre o viaduto era tão bem observado, proporcionando àquele setor da urbe um aspecto realmente triste, numa verdadeira antítese do que é a cidade propriamente dita, pelo menos no seu "coração", onde se erguem, majestosamente, como a querer subir aos céus, modernos e esplêndidos prédios que se prestam tanto aos estabelecimentos comerciais, aos escritórios, aos consultórios, às associações de classe como também de moradias traduzidas em luxuosos apartamentos (CORREIO, 1963, p.17).

A inauguração do "majestoso viaduto, orgulho da engenharia municipal", desta "ciclópica obra" teria sido possível graças à "visão e arrojo do prefeito Miguel Vicente Cury", o que teria proporcionado ao "tráfego nesta parte da urbe a elasticidade de que há muito carecia e ao aspecto urbano soberbas características de cidade que se moderniza". As avenidas Moraes Salles e Senador Saraiva (Imagem 1), "hoje amplas e ultradimensionais avenidas de 30 metros", deixaram ao esquecimento "as estreitas ruazinhas campineiras" que um dia foram, contando também, agora, com uma iluminação "das mais modernas (vapor de mercúrio)", que lhes dava à noite "um aspecto de claros e admiráveis contornos" (Idem, p.5).

A celebração da inauguração do viaduto dilui o drama humano de que se revestiu o processo de sua construção. Desapropriações, demolições de moradias de famílias mais desfavorecidas, desalojamentos inevitáveis, inseguranças, incertezas. Contradições sombrias de uma visão de progresso fundada predominantemente numa racionalidade técnica, funcional.

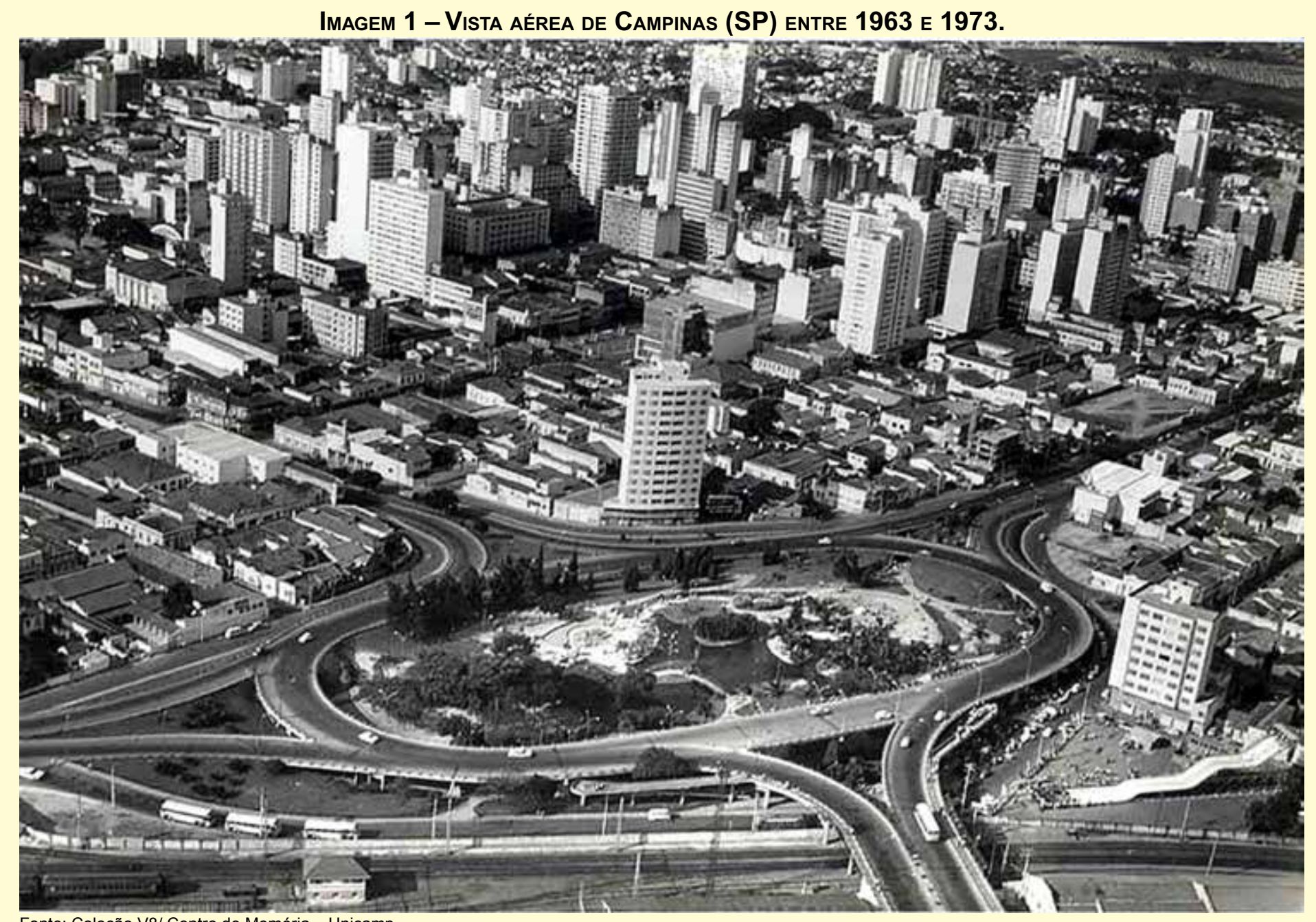

Fonte: Coleção V8/ Centro de Memória - Unicamp

As desapropriações se iniciaram já em 1960. De acordo com o planejamento da obra, 421 imóveis deveriam ser expropriados. O Departamento Jurídico da Prefeitura assumia o compromisso de entregar todos os imóveis devidamente expropriados e desocupados até fim de março de 1961, para que as demolições pudessem ser iniciadas. Por volta de 600 famílias foram atingidas pelas desapropriações, estimando-se 3 mil pessoas desalojadas.

Já em abril de 1961 foi iniciada a "operação-demolição", acompanhada de perto por muitos populares, 
“sob grande curiosidade e ante certo acento emotivo por parte de uns e outros, operários e dirigentes, e especialmente por parte do povo que, em grande massa, assistia à derrubada dos velhos prédios, cada um, quem sabe, com uma história burlesca ou triste para ser contada" (Idem). Além de famílias, casas de comércio, algumas pequenas indústrias e outros estabelecimentos diversos também foram afetados, e precisaram ser transferidos.

Chama a atenção, neste episódio das desapropriações e desocupação dos imóveis, o prazo reduzido destinado a todas estas operações: de meados de 1960 a março de 1961. A construção deste ícone da cidade moderna em que se tornou este viaduto se faz sob o compasso de uma ação que não deixa de ser violenta em relação a grupos sociais mais populares. A imprensa entusiasta da monumentalidade da obra saúda a nova fisionomia do traçado urbano da região central, e as novas avenidas que se articulam às alças laterais do viaduto. A questão social produzida por esse processo de modernização acelerada fica em segundo plano. As referências aos problemas enfrentados pelas famílias desalojadas são feitas sob a perspectiva do elogio "ao humanismo do atual prefeito", e ao Serviço Social instituído para se tratar da questão. Os funcionários deste Serviço Social teriam procurado

[...] sempre esclarecer convenientemente aos atingidos pelas necessidades expropriatórias, ajudando-os muitas vežes a resolver com auxilio material, monetário, os problemas que nas circunstâncias existentes seriam apenas seus, de locação e alojamento, na medida do razoável e do possível (CORREIO, 1963, p. 15).

Chamam a atenção a naturalidade e a crueza destas referências aos problemas sociais propiciados pelo novo viaduto. Os problemas seriam apenas dos desalojados, mas graças a uma suposta generosidade da Prefeitura, muitos estariam sendo tratados na medida do razoável e do possível, já que ela teria prestado um serviço "absolutamente inspirado nos princípios de bumanidade e de preceitos sociais a que não seria obrigada, se se ativesse pura e simplesmente à aplicação dos dispositivos da lei”. O tom destas falas encontradas nos jornais parece expressar um certo diálogo com uma possível parcela da opinião pública, que teria manifestado preocupação com o destino social dos expropriados e com o montante das indenizações pagas, como também suaviza a responsabilidade dos envolvidos no projeto de modernização da cidade. A assistência prestada não aparece explicitamente como um direito social dos atingidos, mas como uma ação humanitária dos poderes públicos. A situação vivenciada pelas famílias desalojadas é interpretada como inevitável, pois “desapropriar é problema que existe em todas as cidades do mundo, porque o progresso e a vida criam novos caminhos, exigem novos traçados nas velhas paisagens". E a cidade de Campinas, "no seu anseio de progresso, enfrenta também esse grande problema, mas tem sabido dar-lhe tonalidade humana"(Idem).

A análise do noticiário do momento da inauguração nos traz algumas formas de atuação de assistentes sociais: famílias eram visitadas para receber esclarecimentos e orientação sobre o que fazer, e para se fazer um levantamento de suas necessidades materiais, o que era levado ao GOV para que os casos fossem avaliados para a concessão de auxílio financeiro. Há referências, também, a fornecimento de medicamentos, doação de material de construção retirado dos imóveis demolidos, e empréstimo de veículos da Prefeitura para auxiliar as mudanças. Todavia, todas essas medidas que parecem suavizar as preocupações e a possível angústia vivida pelas famílias atingidas coexistem com uma postura oficial de concessão de benefícios, uma postura que se arroga o direito de dizer que faz mais do que as leis exigem. A busca do progresso e da modernização atualizada pelas elites urbanas se faz como um valor absoluto, inevitável e inadiável. $\mathrm{Na}$ visão laudatória do enorme progresso técnico representado pela obra do viaduto encontramos traços de práticas de poder que excluem parcelas da população da possibilidade de usufruir algum benefício daquela modernização esperada e cultuada.

O ritmo acelerado das demolições encobria algumas histórias saborosas como a de um 'pinguço' que teria ficado muito surpreso ao atravessar a soleira do "Bar do Otávio":

O olhar admirado vagou pelo azul do céu, buscando em vão as prateleiras apinhadas de garrafas. O corpo tentou apoiar-se no balcão inexistente e sua voz exprimiu o espanto: "ainda na hora do almoço tomei umas pingas aqui. Será que me enganei? Este não é o bar do Otávio?” O bar funcionara até o meio dia. Ao anoitecer já estava no chão. Eram as picaretas do progresso em ação (CORREIO, 1963, p.16). 


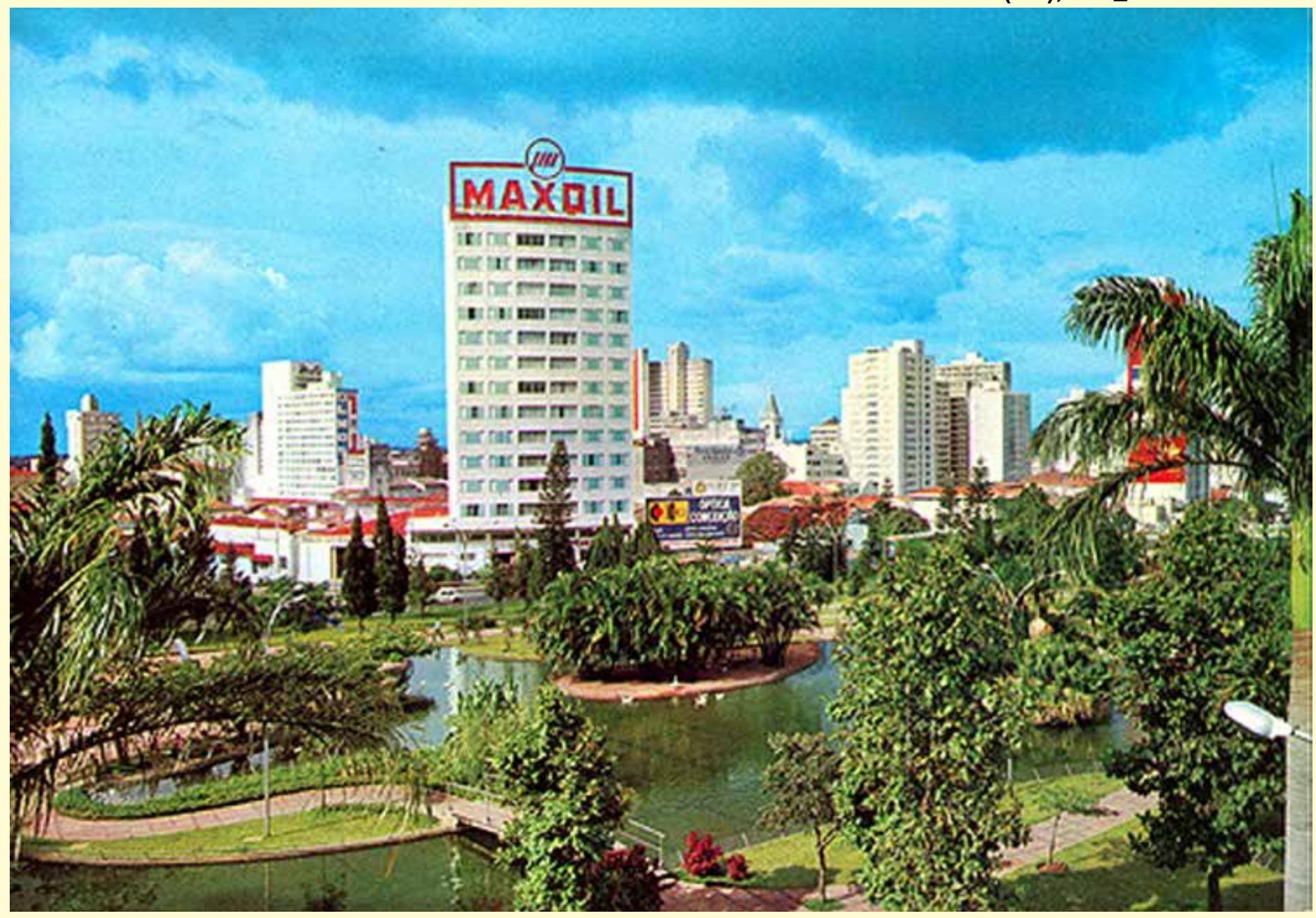

Fonte: Coleção Arthur Pereira Villagelin/Centro de Memória - Unicamp.

Andar de automóvel pelas pistas do viaduto, que neste momento se oferecia como um espetáculo a ser apreciado e contemplado, e passear pelo amplo jardim formado em seu interior, constituiu-se num passeio costumeiro de muitas famílias aos domingos à tarde que também apreciavam contemplar o chamado Lago dos Cisnes deste jardim (Imagem 2).

Que cidade, então, está adquirindo maior visibilidade para seus moradores? Que cidade está sendo anunciada e proclamada pelo novo viaduto que se exibe triunfante com seus jardins e lagos?

A cidade do automóvel está se impondo, tornando menos nítida a presença de diversas outras histórias e memórias neste cenário urbano. Estão sendo criadas mais condições de se estar cada vez mais de passagem por diferentes lugares da cidade, de circulação cada vez mais rápida pelo espaço urbano ao se percorrer de automóvel as novas avenidas e ruas alargadas.

$\mathrm{Na}$ descaracterização em curso do centro urbano, há indícios de que o processo de modificações da área urbana mais central e de imposição de uma outra temporalidade tenha provocado alterações em práticas culturais correntes. Sinais de um processo de desvalorização de formas de sentir e se relacionar com a cidade mais afinados, também, com os ritmos dos bondes que por muitas décadas circularam pelas ruas.

\section{Outras cenas e cenários urbanos}

Em meio, portanto, às transformações da paisagem urbana, marcada, sobretudo, pela presença do automóvel que vai se impondo como a forma predominante de circulação pelas ruas da cidade, a nova temporalidade que está se configurando neste período afeta modos de viver a cidade, provoca alterações de práticas culturais então habituais.

Temos notícia de que, aos poucos, foram rareando os programas ao vivo de emissoras de rádio da cidade, que para isto ocupavam o auditório do Teatro Municipal de Campinas. Estes programas, bastante fre- 
quentes durante a década de 1950 e a primeira metade dos anos 1960, tiveram suas atividades definitivamente encerradas por ocasião da demolição do Teatro em 1965 (JORNAL, 1979) ${ }^{8}$. Campanhas filantrópicas eram realizadas por alguns programas de rádio, como a que ocorre em outubro de 1960, organizada pelo programa "Hora do Trabalhador" da rádio Educadora, em favor do Hospital Álvaro Ribeiro, "onde se acham internadas crianças sem recursos", sendo que "em apenas vinte dias foram arrecadados mais de 70 mil cruzeiros" (DIÁRIO, 1960). Dirigentes da rádio, acompanhados do locutor do programa, fizeram a entrega, pessoalmente, à direção do Hospital. Anos mais tarde, em 1978, um radialista da rádio Cultura, rememorando momentos marcantes da história do rádio campineiro, lamenta a extinção das campanhas filantrópicas realizadas pelas rádios da cidade: "hoje já não se fazem campanhas como antigamente e eu não sei por que razão, talvez seja comodismo" (DIÁRIO, 1978). Situações de contato mais direto com o público estavam se extinguindo.

Uma progressiva diminuição dos locais livres para maior possibilidade de convívio entre as pessoas pode ser observada neste período. Alguns lugares do centro da cidade, costumeiramente locais de maior interação social, vão perdendo essas características e se tornam, principalmente, locais de passagem. A retirada definitiva dos bondes de circulação em 1968 e as reformas urbanas na área central colocaram um fim às possibilidades costumeiras de encontro e de "paquera" que ocorriam frequentemente nas proximidades da "prainha", local de confluência de linhas de bonde nas imediações do largo da Catedral, entre as ruas Treze de Maio e a Francisco Glicério.

Estão sendo operadas redefinições das relações sociais e das relações das pessoas com os diversos lugares da cidade. Em depoimentos colhidos na década de $1990^{9}$, podemos apreender, através das lembranças trazidas por moradores de dois bairros de perfil social diferente de Campinas - Cambuí e Vila Industrial -, os traços de tendências de alteração de maneiras de viver a cidade, provocadas pelo avanço mais acelerado da modernidade neste período.

Sem as preocupações atuais com questões de segurança, era comum conversar até tarde nas calçadas e dormir despreocupadamente com as portas da casa destrancadas. Contatos com vizinhos eram mais frequentes, com situações de ajuda mútua, troca de receitas de remédios caseiros, empréstimos de utensílios. Situações que não eram compartilhadas pelas camadas sociais mais favorecidas que, atingidas mais cedo pelas marcas da impessoalidade e da indiferença, em geral, não cultivavam relações de vizinhança com pessoas que não fossem do mesmo nível social. As brincadeiras das crianças nas ruas eram rotineiras: brincava-se de roda, de rodar pião, de empinar pipa, jogava-se futebol na rua; frequentemente, essas brincadeiras aproximavam os vizinhos, na medida em que os adultos conversavam enquanto observavam os filhos brincando. As ruas eram espaços de convívio, tanto para adultos quanto para crianças.

Se no Cambuí ou em bairros de perfil social semelhante o lazer dos moradores se ligava mais à participação na vida social oferecida pelos clubes, em outros bairros mais populares, como a Vila Industrial, as possibilidades de lazer também eram diversificadas: bater papo e discutir futebol nos inúmeros bares e botequins da Vila ${ }^{10}$, montar time de futebol amador e jogar nos diversos campinhos que por ali se espalhavam, fazer maior uso dos espaços públicos, como praças e calçadas, para criar situações de convivência.

Ir ao cinema no centro da cidade constituía-se em forma de lazer buscada por diferentes grupos sociais. Havia o cine Voga, depois Jequitibá, o Ouro Verde, o Windsor, Regente, Carlos Gomes; filmes mais diferenciados, fora do circuito comercial, podiam ser vistos no auditório do Centro de Ciências, Letras e Artes (CCLA), também localizado na área central. A desvalorização das salas de cinema do centro, que se transfor-

8 Segundo o jornalista Bráulio Mendes Nogueira, em entrevista a este jornal, vários eram os programas que, na década de 50, as emissoras de rádio transmitiam de um auditório, assim como os de calouros ou os shows que se organizavam. O jornalista relata que o Teatro, frequentado até então pela elite, "com o tempo foi se popularizando, certamente com a ajuda do rádio. Verdadeiras torcidas organizadas compareciam ao Municipal, promovendo violentos quebra-quebras quando da apresentação de Emilinha Borba ou Marlene, duas inveteradas rivais estimuladas pela publicidade da época".

9 Esses depoimentos fizeram parte do projeto de pesquisa realizado na década de 1990 "Persistências e mudanças do viver urbano em dois bairros de Campinas: Cambuí e Vila industrial”, com a coordenação geral da Profa. Dra. Olga Rodrigues de Moraes von Simson”, CMU - Arquivos Históricos.

10 Segundo a pesquisa mencionada acima, havia 18 bares na Vila Industrial: Último Gole, Bar do Oscar, Bar da Tita, Bar dona Isabel, Bar do André, Bar da Regina, Bar dos Pretos, Bar Campinas, Bar do Tico, Bar A Garota, Bar do Nestor, Bar do Nacarato, Bar do Aparecido, Bar do Neguinho, Bar do Pão-duro, Bar do Juvenal, Bar Jardim, e Bar da Linguiça. 
Artigos

mam em locais de funcionamento de templos religiosos, de promoção de bingos ou de apresentação de filmes pornôs, ocorre simultaneamente à ampliação e fortalecimento da sociedade de consumo que se observa neste período da sociedade contemporânea de modo geral. A construção de shoppings a partir do início dos anos 70 vai produzir alterações nas formas de lazer: além de ir ao cinema nestes locais supostamente mais seguros, consumir, fazer compras, também se tornam opções de lazer mais regulares.

Pode-se afirmar, portanto, que entre os anos finais da década de 50 e início da de 70, as relações sociais estão sendo ressignificadas, assim como também estão sendo redefinidas as relações das pessoas com os diversos lugares da cidade. Parece ser um momento em que se pode perceber uma acentuação da fragilização dos vínculos que se estabelece com os diferentes lugares da cidade, um momento que tende a favorecer uma maior fragmentação das relações sociais. Momentos estes em que outras formas de sociabilidade e de sensibilidades vão se constituindo e se reafirmando, formas estas que acenam para nossa contemporaneidade mais recente.

As transformações do espaço urbano oferecem suporte material para as imagens que vão sendo produzidas sobre esses momentos da história da cidade. A forma como o espaço urbano se apresenta organizado nestes momentos da modernidade nos remete a pensar nas condições que estes momentos criam para as experiências/vivências urbanas dos diferentes grupos sociais. As imagens das demolições, das novas construções modernas, do alargamento das ruas, da intensa verticalização nas áreas mais centrais da cidade, do amplo crescimento horizontal em direção às periferias, das muitas avenidas, vias expressas, viadutos, com automóveis e ônibus tomando cada vez mais as ruas da cidade, compõem um conjunto de elementos que interferem na constituição do que seja a experiência urbana naquele momento. Repetitivamente, as concepções de moderno e de progresso, veiculadas cotidianamente pela grande imprensa local, são associadas ao desenvolvimento técnico, à verticalização, à presença de muitos automóveis e, portanto, à ideia de movimento e de velocidade. Representações de uma cidade moderna e em constante progresso desfilam enfaticamente pelas páginas de jornais locais. Cotidianamente agem no sentido de uma educação do olhar, na conformação de uma forma de percepção e apreensão da cidade.

No entanto, precisamos também levar em conta outras mediações significativas que se interpõem nos processos de constituição da experiência urbana nos momentos focalizados. É preciso considerar o peso do autoritarismo vigente no país, principalmente a partir de 1964, com o estabelecimento do regime ditatorial. A partir de então, os espaços públicos passam a ser mais vigiados, mais controlados. A censura à imprensa, e aos meios de comunicação de forma geral, que vai se ampliando ao longo da década, impõem um recolhimento maior às pessoas em seus espaços privados. As ruas, antes cenários possíveis de manifestações populares e estudantis, estão sendo objeto de uma vigilância mais constante por parte de agentes do Estado autoritário. As condições políticas de limitação das liberdades pessoais e coletivas se imbricam com os traços da modernidade urbana, desdobrando-se num processo de radicalização das formas de individualismo urbano e de maior dose de impessoalidade e distanciamento nas relações sociais.

A sensibilidade urbana que emerge deste cenário é uma sensibilidade mais afeita ao movimento rápido, ao andar mais apressado, a uma postura mais defensiva em relação a toda sorte de perigos das ruas. O sujeito urbano moderno de Georg Simmel do início do século XX encontra-se mais robustecido em meados do século.

Uma sensibilidade ancorada na percepção da mobilidade das formas da paisagem urbana, da mobilidade dos automóveis e das pessoas. Concretiza-se a ideia do transitório, do efêmero, da mutabilidade, traços fundamentais da movimentação social e cultural da modernidade. A inconstância das formas urbanas passa a ser percebida de modo naturalizado e nesse processo de renovação constante do espaço urbano, a memória da vida urbana tende a se fragilizar - suportes de memória estão sendo derrubados.

Como um meio de comunicação com o espaço urbano, os jornais locais promovem uma circulação regular de visões sobre a cidade, visões estas que se constituem em mediações significativas das formas de percepção da cidade. Neste sentido, posso dizer que as representações da cidade veiculadas pelos jornais fazem parte de uma memória social, compõem um imaginário social, cujos fragmentos se fazem presentes como mediações da apreensão do urbano, constituindo-se numa educação do olhar, numa educação urbana das sensibilidades. Uma forma de educação que se entrelaça com aquela proporcionada pelo circular de automóvel pela cidade. 
A crescente preocupação com a violência urbana, que passa a se fazer presente a partir dos anos 70 , implica em se procurar limitar a convivência das crianças e jovens com as ruas; o contato mais próximo com o "outro" desconhecido tende a ser visto cada vez mais como problemático, ameaçador (SEIXAS, 2009); as pessoas vão tender cada vez mais a se refugiar, a se enclausurar em seus espaços privados. Estas tendências de comportamentos mais reservados se acentuam com a formação dos condomínios residenciais fechados, os quais passaram, nos últimos anos, a se constituir numa forma importante de expansão da área urbana. De forma complementar, as propostas cada vez mais usuais, nos últimos anos, de construir espaços de lazer dentro dos próprios prédios residenciais reforçam um movimento de configuração de espaços segregados na área urbana.

Com os desdobramentos da modernidade em várias instâncias da vida social, assistimos a um certo esvaziamento das possibilidades de relações interpessoais mais próximas. A condição urbana que se desenha a partir do período analisado se apresenta permeada pelas tonalidades da indiferença, da passividade, da postura defensiva. O sujeito urbano moderno vai se aproximando cada vez mais da figura do espectador.

Talvez seja por estar vivenciando estas tendências que se colocam para as relações interpessoais na cidade moderna que um jovem estudante de ensino médio, em 1969, publique num jornal estudantil do colégio onde estuda o que chamou de "Um Triálogo" sobre "o futuro da presente realidade ou como pensar no futuro estando no passado"

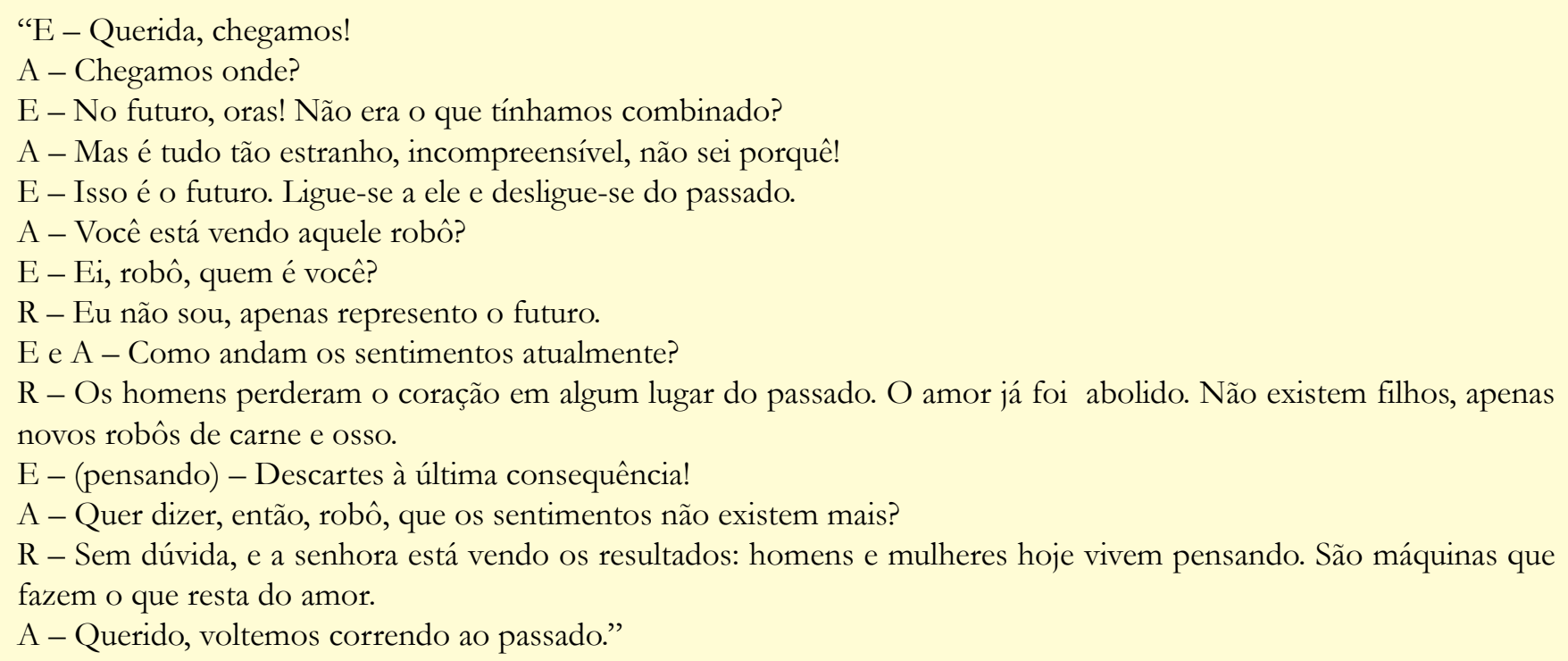

$\mathrm{Na}$ imaginação romantizada do adolescente, sinais da percepção crítica das tendências culturais da época em que estava vivendo. A racionalidade técnica a nortear a construção deste futuro robotizado, em que os sentimentos foram abolidos, uma vez que "os homens perderam o coração em algum lugar do passado". Uma maior impessoalidade das relações sociais parece estar sendo apontada como um caminho que se oferece ao jovem estudante, e que é recusado por ele através desta produção escrita.

Alguns anos mais tarde, em abril de 1974, "numa visão futurista" da Rua Treze de Maio, o editorial de um jornal alternativo - O Foca ${ }^{12}$-, realiza um devaneio sobre o futuro desta movimentada rua comercial do centro da cidade:

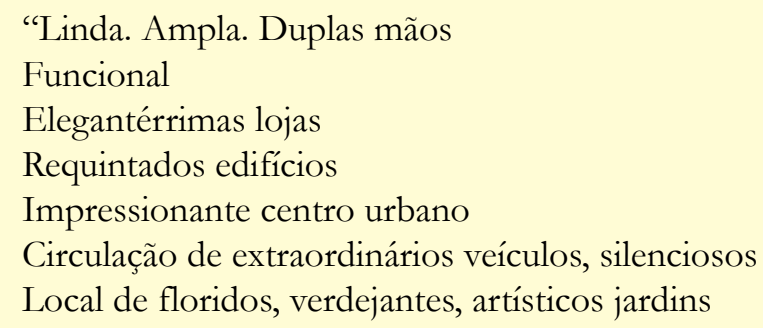

$11 \mathrm{O}$ “Triálogo" ocorre entre três personagens, $\mathrm{E}=\mathrm{ele}, \mathrm{A}=\mathrm{ela}, \mathrm{R}=$ robô. (GRÊMIO, 1969, p.2).

12 FOCA, 1974. 
Tradicional ainda - movimentada sempre

Avenida 13 de Maio:

- uma recordação da então concorrida Estação Fepasa

- uma piedosa lembrança da artística Catedral

- e nem rastros mais do esquipático Viaduto Cury."

O futuro, aqui, se apresenta associado ao movimento incessante, com a roupagem das avenidas, dos edifícios requintados, da circulação de veículos (Imagem3). Na imaginação do jornalista, marcas importantes da história da cidade foram apagadas, suportes desta memória subsistem apenas como meras lembranças.

Se o estudante teme um futuro mais impessoal e tecnicista, o jornalista o celebra. Sensibilidades urbanas diferentes, constituídas e abrigadas pela modernidade em suas movimentações ambivalentes.

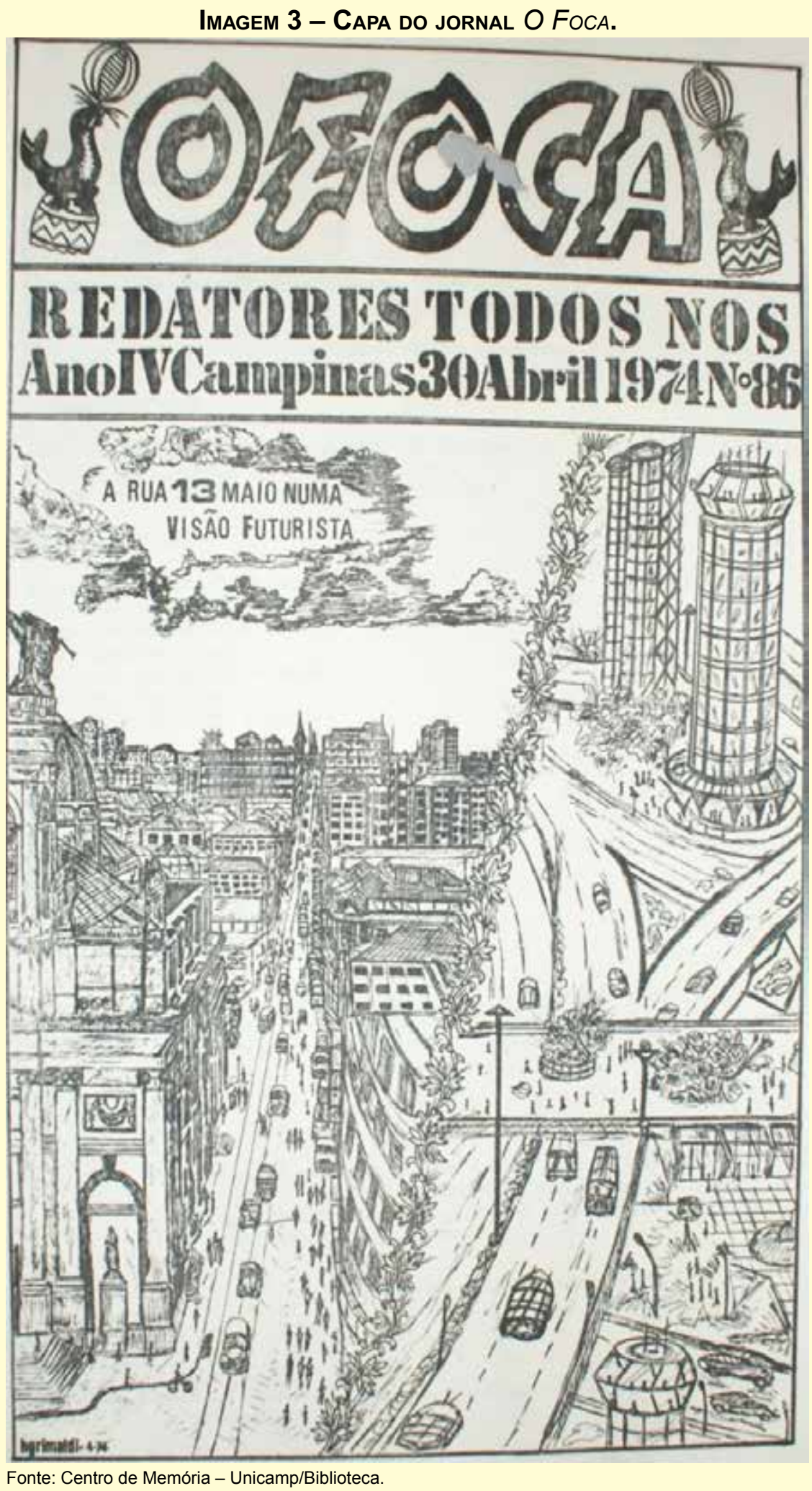


E quanto ao Viaduto Cury, o futuro não apagará seus rastros, como tentou imaginar o jornalista, mas descaracterizou-o enquanto lugar privilegiado do progresso e do moderno. Processos de substituições e descaracterizações operados pelos ritmos acelerados do avanço da modernidade na cidade deterioraram a imagem de cartão postal do Viaduto. O espaço de paisagismo cuidado em torno do lago que nos anos 1960 podia permitir fruição e contemplação dos habitantes não mais existe. Barracas de camelôs e um terminal de ônibus ocupam o espaço em torno do agora velho Viaduto. Outros espaços e avenidas passaram a disputar a atenção dos cartões postais oferecidos aos visitantes da cidade...

O avanço acelerado da modernidade criando condições para a produção de ruínas, para o descarte, para substituições sucessivas do novo pelo mais novo.

\section{Referências}

BAUMAN, Z. Modernidade Liquida. Rio de Janeiro: Jorge Zahar Editor, 2001.

BENJAMIN, Walter. Obras Escolbidas I. Magia e técnica. Arte e política. São Paulo: Brasiliense, 1985. Obras Escolbidas II. Rua de mão única. São Paulo: Brasiliense, 1987.

Obras Escolbidas III. Charles Baudelaire, um lírico no auge ～do capitalismo. São Paulo: Brasiliense, 1989. Passagens. Belo Horizonte: Editora da UFGM; São Paulo: Imprensa Oficial do Estado de São Paulo, 2006.

BRESCIANI, Maria Stella Martins. Cidade, cidadania e imaginário. In: SOUZA, C.F.; PESAVENTO, S.J. (Orgs). Imagens Urbanas. Os diversos olhares na formação do imaginário urbano. Porto Alegre: Editora da Universidade/ UFRGS, 1997.

CARPINTERO, A.C. Momento de ruptura. As transformações no centro de Campinas na década dos cinquenta. Campinas: UNICAMP/CMU, 1996.

CAUQUELIN, Anne. Essai de philosophie urbaine. Paris: PUF, 1982.

CORREIO POPULAR. Suplemento Comemorativo. Campinas, 27 jan.1963.

DIÁRIO DO POVO. Microfone Campineiro. Campinas, 14 nov.1960.

GALZERANI, Maria Carolina Bovério. O almanaque, a locomotiva da cidade moderna. Campinas, décadas de 1870 e 1880. Tese (Doutorado em História), IFCH, UNICAMP, 1998.

A cidade como espaço de aprendizagem da História: em foco um projeto de educação patrimonial. In: SANTOS, Lucíola Licínio de Castro Paixão et al.(Orgs.). Convergências e tensões no campo da formação do trabalho docente. Belo Horizonte: Autêntica, 2010.

GAY, Peter. A experiência burguesa da Rainha Vitória a Freud: a educação dos sentidos. São Paulo: Companhia das Letras, 1988.

GIDDENS, Anthony. As conseqüencias da modernidade. São Paulo: UNESP, 1991.

. Modernidade e identidade. RJ: Zahar, 2002.

HADLER, Maria Sílvia Duarte. Trilhos de Modernidade: memórias e educação urbana dos sentidos. Tese (Doutorado em Educação). Faculdade de Educação, Universidade Estadual de Campinas, Campinas-SP, 2007.

HALL, S. A identidade cultural na pós-modernidade. 11.ed. Rio de Janeiro: DP\&A Editora, 2006.

JORNAL HOJE, Auditório, fãs e roupas rasgadas, Campinas, 18/11/1979.

MONGIN, Olivier. A condição urbana: a cidade na era da globalização. SP: Estação Liberdade, 2009.

GRÊMIO ESTUDANTIL CARLOS GOMES. Colégio Estadual Vítor Meireles de Campinas. O Coruja. Campinas, ano VI, n.1, nov. 1969. 
FOCA. Campinas, ano IV, n.86, 30 abr.1974.

SEIXAS, Jacy Alves. A imaginação do outro e as subjetividades narcísicas - um olhar sobre a in-visibilidade contemporânea [o mal-estar de Flaubert no Orkut]. In: NAXARA, Márcia R.C.; MARSON, Izabel A.; MAGALHÃES, Marion B. (Orgs.). Figurações do outro na história. Uberlândia: EDUFU, 2009, p.63-88.

SENNET, Richard. O declinio do homem público: as tiranias da intimidade. $5^{a}$ reimp. São Paulo: Companhia das Letras, 1998.

. Carne e pedra. Rio de Janeiro: Record, 1997.

SIMMEL, Georg. Metrópole e Vida Mental. In: VELHO, O.G. (Org.). O Fenômeno Urbano. RJ: Zahar Editores, 1976. 